Portland State University

PDXScholar

8-1-2008

\title{
Effect of the California Tobacco Control Program on Personal Health Care Expenditures
}

James M. Lightwood

University of California

Alexis Dinno

Portland State University

Stanton A. Glantz

University of California

Follow this and additional works at: https://pdxscholar.library.pdx.edu/commhealth_fac

Part of the Community Health and Preventive Medicine Commons

Let us know how access to this document benefits you.

Citation Details

Lightwood, J. M., Dinno, A., \& Glantz, S. A. (2008). Effect of the California Tobacco Control Program on Personal Health Care Expenditures. Plos Medicine, 5(8), e178.

This Article is brought to you for free and open access. It has been accepted for inclusion in Community Health Faculty Publications and Presentations by an authorized administrator of PDXScholar. Please contact us if we can make this document more accessible: pdxscholar@pdx.edu. 


\title{
Effect of the California Tobacco Control Program on Personal Health Care Expenditures
}

\author{
James M. Lightwood ${ }^{1,2}$, Alexis Dinno ${ }^{1}$, Stanton A. Glantz ${ }^{1,3^{*}}$ \\ 1 Center for Tobacco Control Research and Education, University of California San Francisco, San Francisco, California, United States of America, 2 School of Pharmacy, \\ University of California San Francisco, San Francisco, California, United States of America, 3 Philip R. Lee Institute for Health Policy Studies and Department of Medicine \\ (Cardiology), University of California San Francisco, San Francisco, California, United States of America
}

Funding: This work was supported in part by National Cancer Institute (grants CA-61021 and CA-113710). The funders had no role in study design, data collection and analysis, decision to publish, or preparation of the manuscript.

Competing Interests: The authors have declared that no competing interests exist.

Academic Editor: Kelley Lee, London School of Hygiene \&

Tropical Medicine, United Kingdom

Citation: Lightwood JM, Dinno A Glantz SA (2008) Effect of the California Tobacco Control Program on personal health care expenditures. PLoS Med 5(8): e178. doi:10.1371/journal.pmed.0050178

Received: February 14, 2008 Accepted: July 11, 2008

Published: August 26, 2008

Copyright: (c) 2008 Lightwood et al. This is an open-access article distributed under the terms of the Creative Commons Attribution License, which permits unrestricted use, distribution, and reproduction in any medium, provided the original author and source are credited.

Abbreviations: $C D C$, United States Centers for Disease Control and Prevention; $\mathrm{CE}$, confidence interval; $\mathrm{CPI}$, consumer price index; $\mathrm{MCP}$ medical care consumer price index; CTCP, California Tobacco Control Program; ECM, equilibrium correction model; FY, fiscal year; SE, standard error

* To whom correspondence should be addressed. E-mail: glantz@ medicine.ucsf.edu

\section{A B S T R A C T}

\section{Background}

Large state tobacco control programs have been shown to reduce smoking and would be expected to affect health care costs. We investigate the effect of California's large-scale tobacco control program on aggregate personal health care expenditures in the state.

\section{Methods and Findings}

Cointegrating regressions were used to predict (1) the difference in per capita cigarette consumption between California and 38 control states as a function of the difference in cumulative expenditures of the California and control state tobacco control programs, and (2) the relationship between the difference in cigarette consumption and the difference in per capita personal health expenditures between the control states and California between 1980 and 2004. Between 1989 (when it started) and 2004, the California program was associated with \$86 billion (2004 US dollars) (95\% confidence interval [CI] \$28 billion to $\$ 151$ billion) lower health care expenditures than would have been expected without the program. This reduction grew over time, reaching $7.3 \%$ (95\% Cl 2.7\%-12.1\%) of total health care expenditures in 2004.

\section{Conclusions}

A strong tobacco control program is not only associated with reduced smoking, but also with reductions in health care expenditures.

The Editors' Summary of this article follows the references.

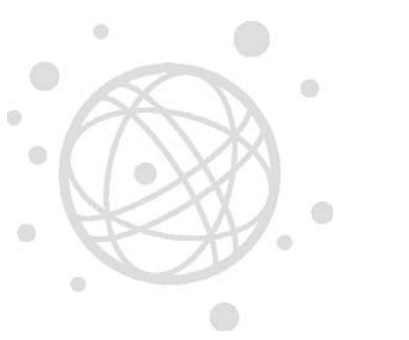




\section{Introduction}

Large-scale tobacco control programs reduce cigarette consumption [1,2] and tobacco-induced heart disease [3] and cancer [4-6]. Despite the availability of large amounts of money from state tobacco taxes and legal settlements with the tobacco industry, little of this money has been invested in tobacco control programs [7,8]. Rapidly increasing health care expenditures are a major problem in the United States and around the world. Increased state and United States health care expenditures have been linked with smoking [911], and would be expected to diminish with reduced smoking, but there has been no direct estimate of the effects of large-scale tobacco control programs on health care expenditures.

The California Tobacco Control Program (CTCP), established in 1989 [12-15], has adopted a comprehensive approach designed to change social norms rather than a frontal attack designed to market cessation services directly to tobacco users. According to key planning documents for the program, this "social norm change" approach seeks "to indirectly influence current and potential future tobacco users by creating a social milieu and legal climate in which tobacco becomes less desirable, less acceptable, and less accessible" [13]. The campaign has combined an aggressive media campaign with three consistent themes-the tobacco industry lies, nicotine is addictive, and secondhand smoke kills [15] — with public policy change, particularly in the area of promoting smoke-free environments. The program differs from many others in that it is focused on adults and social norm change, rather than on adolescent tobacco use prevention, because "in keeping with the social norm change model, the 'next generation' cannot be saved without changing the generations who have already reached adulthood" [13]. The program has been premised on the fact that youth smoking will decline when more adults stop smoking [13]. The program has been functioning continuously at varying levels of intensity since then, which permitted us to investigate the effect of California's large-scale state tobacco control program on aggregate personal health care expenditures in the state.

The determinants of health care expenditures are not a statistically stationary process (i.e., one whose underlying determinants are constant over time) because of changes in medical technology, population mix, and many other variables. Engle and Granger [16] developed the approach of cointegrating regressions that can address this issue, and that describes long-run relationships between nonstationary economic variables over time [17]. We model the relationships between per capita tobacco control expenditures, per capita cigarette consumption, and health care expenditures as a system of two cointegrating regressions to model the long-run relationships and associated equilibrium correction regressions to model short-run relationships [18-20], to assess whether a large-scale tobacco control program is associated with a detectable drop in health care expenditures.

\section{Methods}

\section{Design}

This study used regression analysis of aggregate time series data between 1980 and 2004 on smoking, health care expenditures, and exposure to a tobacco control educational program, in California and a control group of 38 states, to assess the effect of the program on total personal health care spending. The control states were selected because they did not have significant comprehensive tobacco control programs before fiscal year 2000 or cigarette tax increases of $\$ 0.50$ or more per pack over the study period [21] (Alabama, Arkansas, Colorado, Connecticut, Delaware, Georgia, Idaho, Illinois, Indiana, Iowa, Kansas, Kentucky, Louisiana, Maine, Minnesota, Mississippi, Missouri, Montana, Nebraska, Nevada, New Hampshire, New Mexico, North Carolina, North Dakota, Ohio, Oklahoma, Pennsylvania, Rhode Island, South Carolina, South Dakota, Tennessee, Texas, Utah, Vermont, Virginia, West Virginia, Wisconsin, and Wyoming). Total personal health care spending consists of hospital care, physician services, other professional services, dental services, prescription drugs, other health nondurables, vision products and other health durables, home health care, nursing home care, and other personal health care.

Annual per capita all-payer total health care expenditures in California were modeled as a function of corresponding heath care expenditures in the control states and the difference in annual per capita cigarette consumption between California and the control states. This specification controlled for common national trends in per capita health care expenditures and smoking over time (e.g., trends in medical practice, insurance status, access to care, medical cost inflation, demographic changes):

$$
h_{C A, t}=\alpha_{0}+\alpha_{1} h_{\text {control }, t}+\alpha_{2}\left(s_{\text {control }, t}-s_{C A, t}\right)+v_{1, t}
$$

where

$$
\begin{aligned}
h_{i, t}= & \text { per capita real total all-payer health care expendi- } \\
& \text { tures in } i \text { (California or control states) in year } t \text { in } \\
& 2004 \text { US dollars, } \\
s_{i, t}= & \text { per capita cigarette consumption in } i \text { in year } t \text { in } 2004 \\
& \text { US dollars, } \\
v_{1, t}= & \text { stationary residual for year } t \text { in Equation } 1 . \\
t= & \text { year }\left(t_{0}=1980 \text { to } t_{25}=2004\right) .
\end{aligned}
$$

The difference between California and control states' per capita cigarette consumption was modeled as a function of the difference in cumulative per capita California and control state tobacco control expenditures and cigarette prices. Cumulative expenditures were used because some types of expenditures in any given year (e.g., training, community mobilization to effect policy change) are unlikely to change cigarette consumption immediately but will affect it over a longer period and expenditures for specific programs and services (e.g., media interventions, quit lines) may affect consumption several years later, because successful cessation is a process that usually takes many years and multiple quit attempts, and cohorts of youth with decreased initiation rates will slowly enter the population [22]. Thus, we obtain

$$
\begin{aligned}
\left(s_{\text {control }, t}-s_{C A, t}\right)= & \beta_{0}+\beta_{1}\left(E_{C A, t}-E_{\text {control }, t}\right)+\beta_{2} p_{C A, t} \\
& +\beta_{3} p_{\text {control }, t}+\beta_{4}\left(t-t_{0}\right)+v_{2, t}
\end{aligned}
$$

where

$$
\begin{aligned}
E_{i, t}= & \text { cumulative real annual per capita tobacco control } \\
& \text { expenditures in } i \text { (California or the control states) } \\
& \text { in } 2004 \text { US dollars, }
\end{aligned}
$$




$$
\begin{aligned}
p_{i, t}= & \text { average real price per pack of cigarettes in } i \\
& \text { during year } t \text { in } 2004 \text { US dollars, } \\
\left(t-t_{0}\right)= & \text { time, } t \text {, elapsed since } t_{0}=1980, \text { in years, } \\
v_{2, t}= & \text { stationary residual for year } t \text { in Equation } 2 .
\end{aligned}
$$

The linear deterministic trend was included in Equation 2 because a preliminary specification without it produced ambiguous results for unit root tests for stationarity of the cointegrating regression residuals, suggesting the need to include a linear deterministic trend.

These two equations form a recursive system in which tobacco control spending does not directly affect health care spending in the structural relationships. A single reduced form equation could be estimated by substituting the difference in cigarette consumption $\left(s_{\text {control, }}-s_{C A, t}\right)$ out of Equation 1. However, this specification would produce more complicated error terms and severely reduce the degrees of freedom for estimation, so estimation of the structural equations is preferred in this case.

The short-run behavior of variables in a cointegrating relationship is described the by equilibrium correction model (ECM) equations [16,18-20] and at least one ECM equation must exist for each cointegrating regression in the structural system. In this model the ECM equations are

$$
\Delta h_{C A, t}=\gamma_{1} v_{1, t-1}+\gamma_{2} \Delta h_{C A, t-1}+\varepsilon_{1, t}
$$

where

$$
\begin{aligned}
\Delta h_{C A, t}= & \text { first difference of California annual per capita } \\
& \text { health care expenditures } \\
v_{1, t-1}= & \text { lagged residual from Equation } 1 \\
\varepsilon_{1, t}= & \text { normally distributed independent residual, }
\end{aligned}
$$$$
\Delta\left(s_{\text {control }, t}-s_{C A, t}\right)=\eta_{0}+\eta_{1} \mathrm{v}_{2, t-1}+\eta_{2} \Delta\left(s_{\text {control }, t-1}-s_{C A, t-1}\right)
$$$$
+\varepsilon_{2, t}
$$

where

$$
\begin{aligned}
\Delta\left(s_{\text {control }, t}-s_{C A, t}\right)= & \text { first difference of California and controls } \\
& \text { state cigarette consumption at time } t, \\
v_{2, t-1}= & \text { lagged error from cointegration Equa- } \\
& \text { tion } 2, \\
\varepsilon_{2, t}= & \text { normally distributed independent resid- } \\
& \text { ual. }
\end{aligned}
$$

The coefficient $\eta_{0}$ quantifies drift in $\Delta\left(s_{\text {control }, t}-s_{C A, t}\right) ; \gamma_{1}, \eta_{1}$ are the equilibrium (or error) correction terms that quantify the short-run response of the dependent variable to the lagged cointegrating regression residuals, $v_{1, t-1}, v_{2, t-1}$, that describe departures from the long-run relationship described by the cointegrating regressions (Equations 1 and 2) respectively.

Text S1 details the regression methods to estimate the parameters in these equations.

\section{Data Sources (Table S1)}

Annual calendar-year health expenditure data by state of all-payer (1980-2004) and resident (1991-1998) were obtained from Centers for Medicare and Medicaid Services [23] and normalized to 2004 US dollars using the Bureau of the Census resident population intercensal July estimates by state and year [24,25] and the Bureau of Labor Statistics' regional and metropolitan area all-item Consumer Price Index (CPI) and Medical Care Consumer Price Index (MCPI) for all urban consumers [26]. Cigarette consumption data and salesweighted average cost per pack for fiscal year (July-June) were obtained from the Tax Burden on Tobacco [27] and adjusted to 2004 values using the all-item CPI [26].

Population-weighted averages for health care expenditures, per capita cigarette consumption, and price were calculated for the control states using their regional MCPIs, except in the West, where we used a non-California West region MCPI calculated using population weighted California and West region MCPIs [26].

The real annual per capita tobacco control expenditures were obtained for California from the Tobacco Tax Surtax Fund Health Education Account to the California Department of Health Services Tobacco Control Section and California Department of Education [28] by fiscal year and from Farrelly [22] for the average values for the 38 control states, including state funding and funds from the Centers from Disease Control and Prevention and (during the 1990s) the National Cancer Institute ASSIST program [29]. (California did not receive CDC or ASSIST funds.)

\section{Model Reliability and Sensitivity Analyses}

We performed a wide range of tests of model reliability and sensitivity analysis (detailed in Text S1) to ensure that our results were not an artifact of the way the model was formulated or a result of variables that were left out of the model. The focus of these supplementary analyses was to eliminate the possibility that some concurrent process produced the observed differences between California and the control states, for example, earlier and more extensive penetration of managed care in California than in the control states. These analyses included (1) in-sample dynamic predictions of California health expenditure (Equations 1 and 3) and difference in per capita cigarette consumption (Equations 2 and 4); (2) sensitivity analysis of results to choice of controls and price deflators for California health expenditures (Equation 1); (3) out-of-sample forecasts of the dependent (endogenous) variables to check stability of estimated parameters for Equations 1 and 2; (4) reverse regression of cointegrating regressions (Equations 1 and 2); (5) time series modeling of possible untaxed cigarette consumption in California (Equation 1); (6) recursive estimates of the regression coefficients to check model stability over time for Equations 1 and 2; (7) sensitivity analysis of the exogenous time trends; and (8) unrestricted estimation of the effect of changes in per capita cigarette consumption on California health care expenditures in Equation 1.

Additional sensitivity analyses (see Text S1) were performed to determine the robustness of the estimated relationship to alternative estimators; sensitivity analysis of results to inclusion of measures of differences between California and controls, including prevalence of behavioral risk factors (overweight, obesity, hypertension, binge drinking, no regular exercise), demographic factors (white race, Hispanic ethnicity), age structure, health industry structure (cost structure of health care inputs, California versus US managed care penetration, active [licensed] physicians per capita, hospital beds per capita, proportion of population receiving Medicaid services), and economic activity (per capita real personal income) for Equations 1 or 2, or both, as appropriate; alternative time aggregation using calendar and both calendar and fiscal year data; and estimates of stationary distributed lag 
Table 1. Estimated California Personal Health Expenditure and Per Capita Cigarette Consumption

\begin{tabular}{|c|c|c|c|c|c|c|}
\hline Dependent Variable & Equation & Results & $n$ & $R^{2}$ & RMSE & $\begin{array}{l}\text { Autocor- } \\
\text { relation }\end{array}$ \\
\hline \multirow[t]{2}{*}{$\begin{array}{l}\text { California per capita personal } \\
\text { health care expenditures ( } 2004 \$)\end{array}$} & $\begin{array}{l}\text { Cointegrating } \\
\text { regression }\end{array}$ & $\begin{aligned} h_{C A, t}= & \$ 2,736( \pm \$ 173)+0.599( \pm 0.0519) h_{\text {control,t }} \\
& -\$ 27.00( \pm \$ 1.82)(/ \text { pack per capita })\left(s_{\text {control,t }}-s_{C A, t}\right) \\
& +v_{1, t}\end{aligned}$ & 25 & 0.91 & 46.0 & 0.09 \\
\hline & $\begin{array}{l}\text { Equilibrium correction } \\
\text { model }\end{array}$ & $\begin{aligned} \Delta h_{C A, t}= & -0.759( \pm 0.390) v_{1, t-1} \\
& +0.481( \pm 0.221) \Delta h_{C A, t-1}+\varepsilon_{1, t}\end{aligned}$ & 23 & 0.21 & 71.9 & 0.11 \\
\hline \multirow[t]{2}{*}{$\begin{array}{l}\text { Difference in cigarette consumption } \\
\text { in California and control states } \\
\text { (packs per capita) }\end{array}$} & $\begin{array}{l}\text { Cointegrating } \\
\text { regression }\end{array}$ & $\begin{aligned}\left(s_{\text {control, }, t}-s_{C A, t}\right)= & 30.3( \pm 2.15)+0.261( \pm 0.0780)(\text { packs per capita }) / \\
& (\$ \text { per capita })\left(E_{C A, t}-E_{\text {control,t }}\right)+11.3( \pm 2.20) \\
& (\text { packs per capita }) /(\$ \text { per pack }) p_{C A, t}-22.6( \pm 2.90) \\
& (\text { packs per capita }) /(\$ \text { per pack }) p_{\text {control,t }}+1.69( \pm 0.187) \\
& (\text { packs per capita/year })(t-1980)+v_{2, t}\end{aligned}$ & 25 & 0.98 & 1.75 & $-0.23^{a}$ \\
\hline & $\begin{array}{l}\text { Equilibrium correction } \\
\text { model }\end{array}$ & $\begin{aligned} \Delta\left(s_{\text {control }, t}-s_{C A, t}\right)= & 0.946( \pm 0.404)-0.960( \pm 0.232) v_{2, t-1} \\
& +0.315( \pm 0.185) \Delta\left(s_{\text {control }, t-1}-s_{C A, t-1}\right)+\varepsilon_{2, t}\end{aligned}$ & 23 & 0.46 & 1.57 & -0.04 \\
\hline
\end{tabular}

Parameter estimates ( \pm standard errors).

$h_{i, t}$, annual per capita health care expenditures in year $t$ (2004\$).

$s_{i, t}$, annual cigarette consumption (packs per capita).

$E_{i, t}$, cumulative tobacco control program expenditures in $i$ (California or control states) through year $t$ (2004\$).

Autocorrelation: first order autocorrelation coefficient of ACF.

${ }^{a}$ Statistically significant auto-correlation in residuals at $5 \%$ significance level, Box-Ljung Q test, which appear to constitute moving average process at 2 nd and 3 rd lag.

doi:10.1371/journal.pmed.0050178.t001

models for CTCP expenditures in Equation 2. None of these analyses materially affected the results.

\section{Estimation of Aggregate Effects on California Cigarette Consumption and Health Care Costs}

To estimate the aggregate effect of the CTCP on cigarette consumption and total personal health expenditures, we used the parameter estimates and associated standard errors (SEs) in Table 1 from the cointegrating and ECM regressions (Equations 1-4) to construct 10,000 Monte Carlo simulations of cigarette consumption and health care expenditure differences between California and control states with the actual tobacco control program expenditures and with those expenditures set to zero (using the R 2.6.1 [30] statistical software package). The dependent variables in the simulations were initialized with observed values of personal health care expenditures in California and the control states, observed difference in annual cigarette consumption between California and the control states, cumulative tobacco control expenditure data, and annual cigarette price data for fiscal years 1980-1983. Per capita results were multiplied by the population of California and adjusted to 2004 US dollars using the MCPI for health care costs and the CPI for cigarette costs.

To evaluate the effects of declining funding for the CTCP, we repeated the estimations assuming that the CTCP was funded at the same per capita level as the average of the first 3 y of the program (\$4.76 per capita in 2004 US dollars).

\section{Results}

\section{Estimates and Hypothesis Tests}

Both per capita health expenditures in the control states and the difference in per capita cigarette consumption between the control states and California are highly significant predictors of California per capita health care expenditures and fit the data well (Figure 1; Table 1). An increase of one pack per capita per annum consumption of cigarettes is estimated to increase per capita health care costs by $\$ 27.00$ (SE $\$ 1.82$ ).

Both average California and control cigarette prices have a significant effect on the difference in cigarette consumption
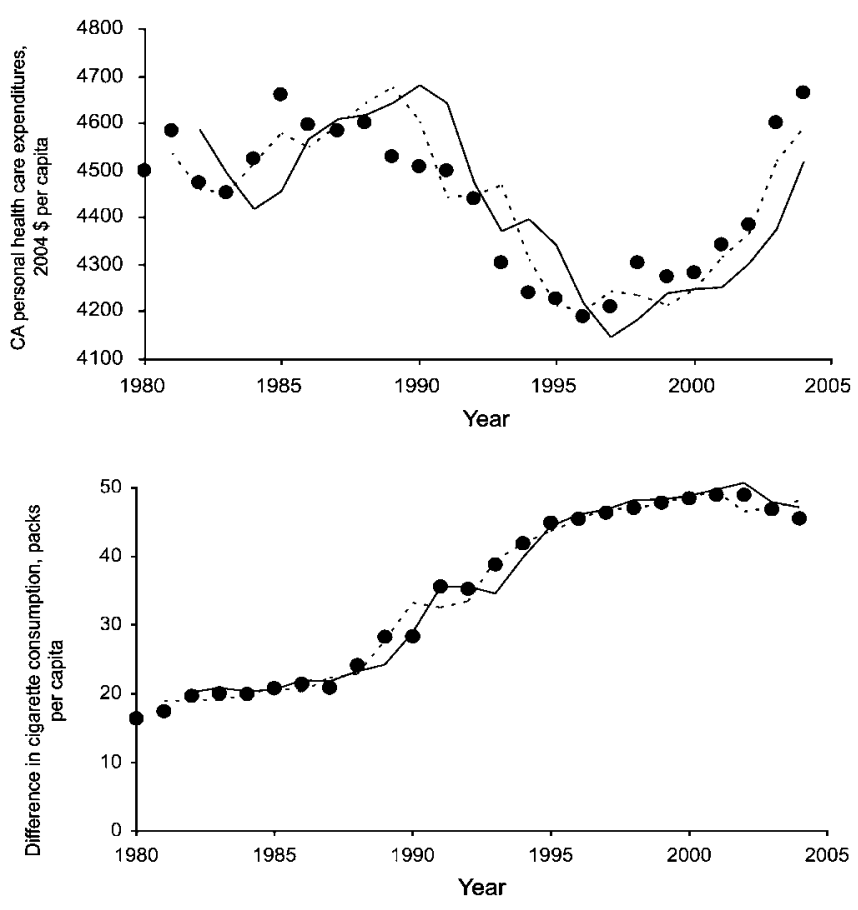

Figure 1. California Personal Health Care Expenditures and Difference in Cigarette Consumption between Control States and California

Endogenous variables per capita California personal health care expenditures $h_{C A, t}$ (top graph), and difference in per capita cigarette consumption between the control states and California, $\left(s_{\text {control, } t}-s_{C A, t}\right)$ (bottom graph), are generated from the estimated model equations and observed exogenous variables using dynamic predictions, and follow the observed values (dots) of the dependent variables closely. The dotted lines are the predicted long-run cointegrating relationships (Equations 1 and 3 ) and the solid lines add the short-run fluctuations from the ECM (Equations 2 and 4) to the long-run predictions. doi:10.1371/journal.pmed.0050178.g001 

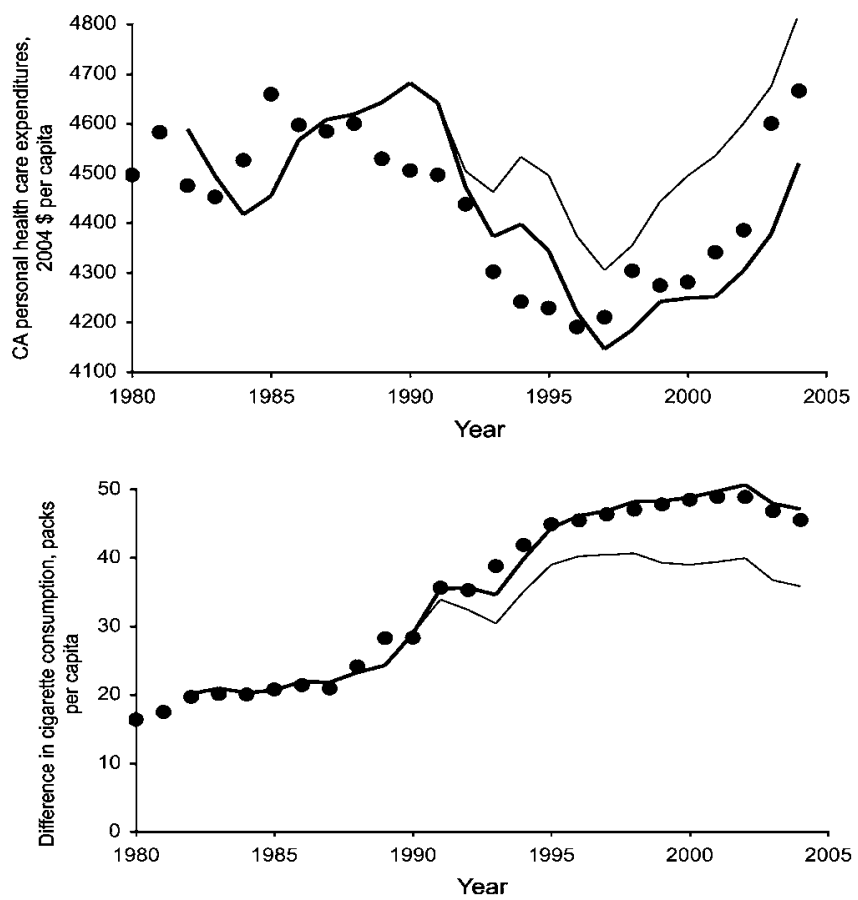

Figure 2. Effect of California Tobacco Control Program on Personal Health Care Expenditures and Cigarette Consumption

The observed (dots) and predicted personal health care expenditures (top graph) and difference in cigarette consumption between the control states and California (bottom graph) with (darker lines) and without (lighter lines) tobacco control expenditures show that the program had a substantial effect on both variables. The dynamic predictions of per capita California health care expenditure, $h_{C A, t}$ uses predicted values for difference in cigarette consumption, $\left(s_{\text {control, } t}-s_{C A, t}\right)$, that are generated by dynamic predictions using Equations $1-4$. The endogenous variables $h_{C A, t}$ and $\left(s_{\text {control, } t}-s_{C A, t}\right)$ are generated from the estimated equations and observed exogenous variables for these dynamic predictions. In this figure the prediction for California health care expenditure uses predicted difference in cigarette consumption from Equations 2 and 4 as an explanatory variable rather than observed (as it was in Figure 1, top graph), which increases the prediction error in this more vigorous test of the model. The vertical differences between the darker and lighter solid lines show the effect of the CTCP expenditures.

doi:10.1371/journal.pmed.0050178.g002

between California and the control states (Figure 1 bottom; Table 1), and are consistent with the interpretation of Equation 2 as a demand relationship. An increase of $\$ 1.00$ in cumulative per capita California tobacco control expenditures over that in control states was associated with a decrease in per capita cigarette consumption of 0.261 (SE 0.078) packs per capita compared to control states. The price coefficients imply moving average arc long-run price elasticities of demand between $0.30-0.45$ (control) and 0.30-0.70 (California) before 1998. Elasticities for both groups increased rapidly after the substantial price increases beginning in 1999 to approximately unity.

The estimated error terms for both Equations 1 and 2 were stationary, indicating that the estimated equations were cointegrating and that statistical inference on the parameter estimates is valid. The estimated error terms for Equation 1 were normally distributed and there were no apparent outliers or serial correlation, but this was not the case for Equation 2. Therefore, alternative estimators were used for Equation 2 that provided robust parameter estimates; these did not change the results significantly.

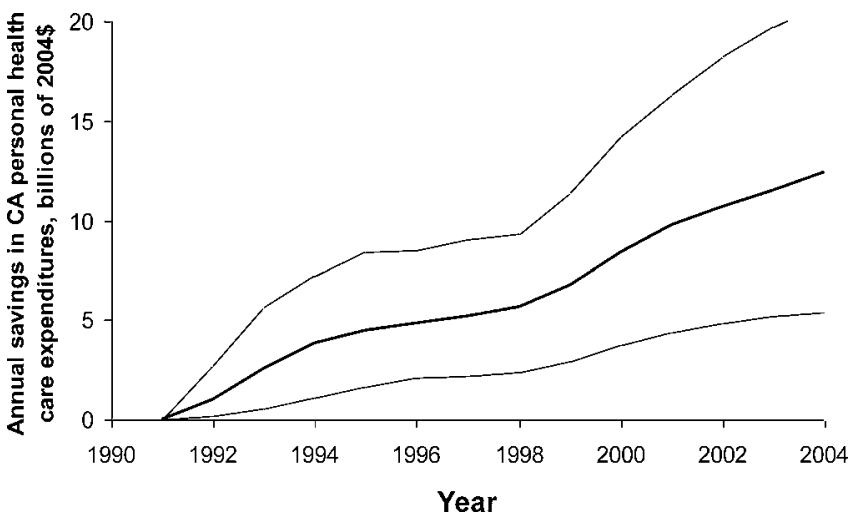

Figure 3. Savings in Personal Health Care Expenditures

The estimated annual personal health care expenditures savings associated with the CTCP began to appear shortly after the program began and grew over time. (Lighter lines indicate the 95\% Cl for the annual savings.)

doi:10.1371/journal.pmed.0050178.g003

The error correction terms in terms of in both ECM equations $\left(\gamma_{1}\right.$ and $\left.\eta_{1}\right)$ are significant and just below -1 , indicating rapid adjustment to the long-run equilibrium values. Parameter estimates in the ECM equations were less certain due to small sample size and square root of sample size convergence of coefficient estimates with stationary variables. The estimates of the ECM model (Table 1) were well behaved for the cointegrating regression for health care expenditure (Equation 1) and had uncorrelated normally distributed residuals. The ECM residuals for Equation 2 were non-normal because of several outliers, two of which were influential. The parameter estimates for Equation 2 did not change significantly with the use of robust estimation techniques such as quantile regression and Huber robust regressions or deletion of the effect of the observations causing the outliers.

\section{Cumulative Effect of the California Tobacco Control Program}

The estimated total savings in personal health care expenditure between the start of the CTCP in fiscal year (FY) 1989-1990 and FY2003-2004 is $\$ 86$ billion (2004 US dollars) (95\% CI $\$ 28$ billion to $\$ 151$ billion) and generally grew over time (Figures 2 and 3), reaching $7.3 \%$ of the total in FY2003-2004, after the program had been running for $15 \mathrm{y}$. This $\$ 86$ billion in reduced health care costs represents about a 50 -fold return on the $\$ 1.8$ billion (in 2004 US dollars) spent on the CTCP during the same period.

The CTCP was also associated with 3.6 billion (95\% CI 1.5 billion to 5.9 billion) fewer packs of cigarettes being sold between FY 1989-1990 and FY 2003-2004 than would be predicted without the program (Figure 2 bottom), representing a loss to the tobacco industry of $\$ 9.2$ billion (95\% CI $\$ 3.8$ billion to $\$ 14.7$ billion) in 2004 US dollars in pre-tax cigarette sales.

The CTCP experienced substantial diversions of funding, particularly in the mid-1990s [31], and the available funds are losing purchasing power due to inflation because it is funded with a constant tax of $\$ 0.05$ per pack. Had the program been maintained at the same level of purchasing power as it had during the first $3 \mathrm{y}$ of the program (averaging $\$ 4.76$ per capita 
per year in 2004 US dollars, which is still well below the level the US Centers for Disease Control and Prevention [CDC] recommends for California [2]), we estimate that the total savings in personal health expenditures would have increased to $\$ 156$ billion (95\% CI $\$ 52$ billion to $\$ 267$ billion), an additional $\$ 70$ billion in health cost savings. This scenario would have required providing an additional $\$ 1.2$ billion over the 15 -y period, about $\$ 80$ million a year in additional funds in 2004 US dollars, to obtain an additional $\$ 70$ billion in health care cost savings.) At the same time, this higher level of funding for tobacco control would have increased the drop in cigarette consumption to 6.6 billion packs (95\% CI 2.7 billion to 10.6 billion), with a corresponding loss in pretax revenue to the tobacco industry of $\$ 16.7$ billion 2004 US dollars $(95 \%$ CI $\$ 7.0$ billion to $\$ 26.9$ billion).

\section{Discussion}

Our estimates confirm earlier work demonstrating that the CTCP has reduced smoking in California relative to other states, and demonstrate, for the first time, that these reductions are associated with substantial, rapid, and growing reductions in per capita state health care expenditures. The medical expenditure savings begin to appear quickly and grow over time and are about 50 times the expenditures of the CTCP.

\section{Comparisons with Other Cost Estimates of Smoking}

The range of cigarette price elasticities we observed prior to 1999 is consistent with previous estimates of long-run elasticities using panel data and generalized methods of moments estimates [32,33]. (The authors are not aware of a substantial literature on the response of elasticity after the price increases immediately preceding the year 2000 , so it was not possible to evaluate the implied elasticities for this period.) The coefficient of the deterministic time trend of 1.69 packs per capita per year (SE 0.187) suggests a long-run divergence of California and control states per capita cigarette consumption, holding other factors constant (including the effect of the CTCP).

The cost estimate of the annual reduction in per capita health care costs of $\$ 27.00$ per pack per capita consumed seems very high if inappropriately interpreted to be the cost of each pack consumed by current smokers. The CDC estimated an excess health care cost per active smoker of $\$ 3,036$ annually (in 2004 US dollars) [11]. Per capita consumption in the US during 2004 was 90.7 packs [34] and smoking prevalence was $20.4 \%$ (SE $0.3 \%$ computed using the delta method) [35], which implies direct health costs of $\$ 6.88$ (SE \$0.11) per pack, consistent with previous estimates $[10,36]$. The regression estimates presented here model the difference between California and control state costs; therefore, the difference between per capita cigarette consumption is the appropriate number to use to convert from per pack to per capita costs. Using our data over the observation period, the mean difference between California and average control state consumption was 34.3 packs per capita, mean California smoking prevalence in $1992-1993$ was $19.4 \%$ (SE $0.3 \%$ ), and mean control state prevalence for the same years was $23.9 \%$ (SE $0.1 \%$ ) [37]. Therefore, the base case control state estimate of $\$ 27.00$ (SE $\$ 1.82$ ) implies an annual cost of smoking per capita of $\$ 27.00 /$ (pack per capita) $\times 34.3$ packs per capita $=\$ 926$, and a cost per smoker of between $\$ 926 /$ $0.239=\$ 3,940(\mathrm{SE} \$ 266)$ and $\$ 926 / 0.194=\$ 4,800(\mathrm{SE} \$ 330)$. Existing estimates of the cost of smoking per pack and per smoker referenced above are probably too low, because they omit (1) recently discovered health effects of smoking (for example, several vision impairments, periodontal disease, colorectal cancer, and risk of dementia in old age); (2) effects of passive smoking on older children and adolescents; and (3) recent quasi-experimental evidence that the coronary effects of passive smoking may be underestimated. Thus, the estimate of the total health cost per pack of cigarettes implied by our analysis is consistent with, and probably more accurate than, earlier estimates based on the costs of some of the specific smoking-related diseases. This estimate includes health costs borne by both active and passive smokers.

\section{Limitations}

Per capita cigarette consumption is not the sole determinant of risk for smoking-related disease; daily smoking status, age at initiation, and time since cessation all affect individual risks. While all these variables-as well as exposure to secondhand smoke-have been affected to varying degrees by the CTCP, we cannot disaggregate the contributions of these different mediating variables to the observed changes.

The specification of Equations 1 and 2 are quite simple, therefore the possible effects of omitted variable bias is a concern. The order of integration of potential confounding variables helps resolve this issue in nonstationary regression. The coefficients of the cointegrating regression will not be biased if the omitted variables are stationary [19]. Therefore we concentrated only on potential confounders that were nonstationary. As noted above, exploratory regression analyses suggested that including any such potential confounders for which data were available did not significantly affect the results. Confounding due to unobserved differences between California health care industry and demographics is possible; however, adjustment for differences in proportion of elderly population, per capita income, managed care market share, and other variables did not change our conclusions (see Text S1).

The measure of cigarette consumption is indirect. State warehouse removals are used as proxies for state cigarette consumption and smoking intensity, and does not account for sales to nonresidents and tax avoidance. If the pattern of untaxed interstate cigarette transfers is relatively stable, then they can be included in the analysis, but would require disaggregated data and other statistical methods. Including several models of untaxed cigarettes, however, did not affect the results (see Text $\mathrm{S} 1$ ).

\section{Implications for Future Research}

The generalizability of this method using aggregate data will depend upon availability of relatively complete and consistent time series data and the pattern of common statistic trends in states or countries to be compared. Where appropriate data are available aggregate time series analysis can be an important supplement to the use of synthetic model-based simulation estimates that have been the principal approach in the past [38]. The use of time series analysis allowed estimates of program effect with fewer assumptions that are difficult to verify than in these synthetic estimates. The use of time series methods can also be used to develop 
forecasts as an additional tool for program planning and evaluation.

The sensitivity analyses did not reveal any additional explanatory variables that changed the coefficient estimates of the two cointegrating regressions. Other variables were identified that appear to partially determine California and control states per capita health care expenditure: the proportion of population that is elderly, the managed care market penetration rate, and the proportion of population receiving Medicaid services. However, including these variables in Equation 1 did not affect the results significantly, and they appeared to form a separate cointegrating regression relationship.

\section{Implications for Public Policy and Tobacco Control Program Design}

It is a testament to the power of the tobacco industry [39] that few US states or countries make substantial investments in aggressive tobacco control programs given the rapid and substantial benefits they produce. For example, in the US, where the states receive about $\$ 25$ billion a year from the 1998 Master Settlement Agreement [7,40] that ended state litigation against the tobacco industry and tobacco taxes, only $\$ 720$ million will be devoted to tobacco control programs in fiscal year 2008 [8], well below the levels that the CDC recommends [2]. Our results suggest that funding these tobacco control programs at the levels that the CDC recommends would rapidly reduce total personal heath care expenditures by hundreds of billions of dollars.

The fact that CTCP has been focused on social norm change among adults, not primarily on youth prevention [13], is probably why it was associated with such rapid and large reductions in disease and the associated health care costs. A program focused on primary prevention of smoking among adolescents would take decades to have any impact on tobacco-induced diseases, which rarely manifest among adolescents or even young adults. The rapid declines in adult smoking and cigarette consumption explain why the program was associated with rapid drops in heart disease [3] and cancer [4-6] and, so, associated health care costs. This approach also led to large reductions in youth smoking. A program concentrated primarily on youth and primary prevention would not have such large rapid benefits.

Our results also suggest that inflation erodes the purchasing power of a fixed amount of money and calls into question the practice of allocating a fixed fraction of a fixed (in current dollar terms) excise tax on cigarettes to tobacco control programs. The erosion of purchasing power due to the fact that the funding for the CTCP has been at a constant $\$ 0.05$ per pack of cigarettes means that tens of billions of dollars of likely health care expenditure savings have been lost. When tobacco control programs are financed by tobacco taxes, the tax should be indexed to inflation to prevent this erosion of program effectiveness over time.

Public health policy makers and advocates need to understand that achieving these gains in health and reductions in health care expenditures comes at a substantial cost to the tobacco industry. The 3.6 billion packs of cigarettes that the CTCP prevented from being smoked represented a loss to the tobacco industry of $\$ 9.2$ billion in pretax sales. In addition, a key element of the program has been to confront the tobacco industry directly $[13,15]$ to reduce smoking initiation and promote cessation attempts [41]. Therefore, it is not surprising that the tobacco industry and its political allies [31] are highly motivated to see that money is not allocated to these programs and that what money is allocated is spent as inefficiently as possible, such as by focusing efforts on young children. Successfully realizing the potential of large-scale, aggressive tobacco control programs will require public-health professionals to pursue advocacy strategies that are commensurate with the opposition that these economic stakes warrant.

\section{Conclusion}

Between 1989, when it started, through 2004, the CTCP was associated with a substantial reduction in total health costs (\$86 billion in 2004 US dollars). Two of the defining characteristics of the CTCP have been its focus on the general population (as opposed to primary prevention in youth) and its promotion of social norm change, particularly smoke-free environments [13]. This focus probably contributed to the substantial effect on health care expenditures, since reductions in adult smoking lead to immediate effects on health costs, whereas primarily prevention of youth smoking would take decades to have any substantial effect on health outcomes. The fact that the program reduced pretax sales of cigarettes substantially over the same time explains why the tobacco industry has worked so hard to roll back the program or limit its scope to youth [31]. The $\$ 86$ billion in health cost savings represents a strong return on the public investment in the program.

While this analysis is based on California, we feel our findings support the use of public policy interventions to reduce tobacco consumption in other settings, and that reductions in tobacco consumption will soon be followed with substantial impacts on health care expenditures. Similar results would be expected in other developed and developing countries, with the specific amount of health care savings depending on how expensive the medical care system is.

A strong tobacco control program can not only reduce smoking, prevent disease, and save lives, but represents an important way to curb rapidly increasing health care expenditures in the short term.

\section{Supporting Information}

Alternative Language Abstract S1. Chinese Translation of the Abstract by Quan Gan

Found at doi:10.1371/journal.pmed.0050178.sd001 (27 KB DOC).

Alternative Language Abstract S2. French Translation of the Abstract by Iana Simeonov

Found at doi:10.1371/journal.pmed.0050178.sd002 (24 KB DOC).

Alternative Language Abstract S3. German Translation of the Abstract by Nick Schneider

Found at doi:10.1371/journal.pmed.0050178.sd003 (28 KB DOC).

Alternative Language Abstract S4. Polish Translation of the Abstract by Maciej Goniewicz

Found at doi:10.1371/journal.pmed.0050178.sd004 (21 KB DOC).

Alternative Language Abstract S5. Spanish Translation of the Abstract by Joaquin Barnoya

Found at doi:10.1371/journal.pmed.0050178.sd005 (26 KB DOC).

Alternative Language Abstract S6. Russian Translation of the Abstract by Teymur Suleyman

Found at doi:10.1371/journal.pmed.0050178.sd006 (21 KB DOC). 
Table S1. Data Used for Analysis

Found at doi:10.1371/journal.pmed.0050178.st001 (93 KB PDF).

Text S1. Additional Methodological Details and Sensitivity Analysis Found at doi:10.1371/journal.pmed.0050178.sd007 (219 KB PDF).

\section{Acknowledgments}

We thank Matthew Farrelly, Kristen Lum, and Yogi Hendlin for assistance in gathering the data on the control state expenditures.

Author contributions. JML developed the cointegrating regression model and did all the calculations to fit the model and do the model validity and reliability tests. AD collected some of the data and performed the Monte Carlo simulations to estimate savings associated with the CTCP and the associated confidence intervals. SAG formulated the general question and the conceptual model. All three authors contributed to preparing the manuscript for submission.

\section{References}

1. Institute of Medicine (2007) Ending the tobacco problem: A blueprint for the nation. Washington (D. C.): National Academies Press.

2. Centers for Disease Control and Prevention (2007) Best practices for comprehensive tobacco control programs-2007. Atlanta (Georgia): US Department of Health and Human Services, Centers for Disease Control and Prevention, National Center for Chronic Disease Prevention and Health Promotion, Office on Smoking and Health. Available: http://www. cdc.gov/tobacco/tobacco_control_p programs/stateandcommunity/ best_practices/index.htm. Accessed 18 June 2008.

3. Fichtenberg CM, Glantz SA (2000) Association of the California Tobacco Control Program with declines in cigarette consumption and mortality from heart disease. N Engl J Med 343: 1772-1777.

4. Centers for Disease Control and Prevention (2000) Declines in Lung Cancer Rates-California, 1988-1997. MMWR Morb Mortal Wkly Rep 49: 1066-1069.

5. Jemal A, Cokkinides VE, Shafey O, Thun MJ (2003) Lung cancer trends in young adults: an early indicator of progress in tobacco control (United States). Cancer Causes Control 14: 579-585.

6. Barnoya J, Glantz S (2004) Association of the California Tobacco Control Program with declines in lung cancer incidence. Cancer Causes Control 15: 689-695.

7. Schroeder S (2004) Tobacco control in the wake of the 1998 master settlement agreement. N Engl J Med 350: 293-301.

8. Campaign for Tobacco Free Kids (2007) A broken promise to our children The 1998 State Tobacco Settlement nine years later. Washington (D. C.): Campaign for Tobacco Free Kids. Available: http://www.tobaccofreekids org/reports/settlements/2008/fullreport.pdf. Accessed 18 July 2008.

9. Office of Technology Assessment (1985) Smoking-related deaths and financial costs. Washington (D. C.): Office of Technology Assessment, U.S Congress.

10. Warner KE, Hodgson TA, Carroll CE (1999) Medical costs of smoking in the United States: estimates, their validity, and their implications. Tob Control 8: $290-300$.

11. [No author listed] (2002) Annual smoking-attributable mortality, years of potential life lost, and economic costs-United States, 1995-1999. MMWR Morb Mortal Wkly Rep 51: 300-303.

12. Bal DG, Kizer KW, Felten PG, Mozar HN, Niemeyer D (1990) Reducing tobacco consumption in California. Development of a statewide antitobacco use campaign. JAMA 264: 1570-1574.

13. Tobacco Control Section (1998) A model for change: The California experience in tobacco control. Sacramento (California): California Department of Health Services. Available: http://www.cdph.ca.gov/programs Tobacco/Documents/CTCPmodelforchange1998.pdf. Accessed 18 July 2008

14. Bal DG, Lloyd JC, Roeseler A, Shimizu R (2001) California as a model. J Clin Oncol 19: 69S-73S.

15. California Tobacco Education and Research Oversight Committee (TER OC) (2000) Toward a TOBACCO-free California: Strategies for the 21st Century 2000-2003. Sacramento (California): California Department of Health Services. Available: http://www.cdph.ca.gov/programs/Tobacco/ Documents/CTCPMasterPlan00-03.pdf. Accessed 18 July 2008.

16. Engle R, Granger C (1987) Co-integration and error correction: Representation, estimation and testing. Econometrica 55: 251-276.
17. Granger CWJ (2003, December 8) Time series analysis, cointegration, and applications [Nobel Lecture]. Available: http://nobelprize.org/nobel_prizes/ economics/laureates/2003/granger-lecture.pdf. Accessed 7 February 2008.

18. Burke SP, Hunter J (2005) Modelling non-stationary economic time series: A multivariate approach. New York (New York): Palgrave McMillan.

19. Maddala GS, Kim I-M (1998) Unit roots, cointegration, and structural change. Cambridge (UK): Cambridge University Press.

20. Tsay RS (2005) Analysis of financial time series. Hoboken (New Jersey): John Wiley \& Sons.

21. Abadie A, Diamond A, Hainmueller (2007) Synthetic control methods for comparative case studies: Estimating the effect of California's Tobacco Control Program. National Bureau of Economic Research. Available: http:// ideas.repec.org/p/nbr/nberwo/12831.html. Accessed 18 July 2008.

22. Farrelly MC, Pechacek TF, Thomas KY, Nelson D (2008) The impact of tobacco control programs on adult smoking. Am J Public Health 98: 304309.

23. Centers for Medicare and Medicaid Services (2007) Health expenditures by state of provider: Summary Tables, 1980-2004 (Final, February 2007). Available: http://www.cms.hhs.gov/NationalHealthExpendData/ 05_NationalHealthAccountsStateHealthAccounts.asp\#TopOfPage. Accessed 5 May 2007.

24. [No author listed] (2004) Resident Population for Selected Age Groups: 1980 to 1989: United States Bureau of the Census. Available: http://www. census.gov/popest/archives/1980s/estage80.txt. Accessed 7 December 2007.

25. [No author listed] (2008) State resident population by age and sex, 20002006: United States Bureau of the Census. Available: http://www.census.gov/ popest/states/asrh/files/SC_EST2005_AGESEX_RES.csv. Accessed 7 December 2007.

26. Bureau of Labor Statistics (2007) Consumer Price Index-All urban consumers (current series). Bureau of Labor Statistics. Available: http:/l www.bls.gov/cpil. Accessed 18 July 2008.

27. Orzechowski \& Walker (2005) Tax Burden on Tobacco: Historical Compilation, vol. 40. Arlington (VA): Orzechowski \& Walker.

28. California Department of Health Services (2007) Proposition 99 Health Education Account, TCS Funding, CDE, and TRDRDP Budget Appropriation Summary.

29. National Cancer Institute (2005) ASSIST: Shaping the future of tobacco prevention and control. Bethesda (Maryland): National Cancer Institute Smoking and Health Monograph 16. NIH Pub. No. 05-5645. Available: http://cancercontrol.cancer.gov/TCRB/monographs/16/index.html. Accessed 18 July 2008.

30. R Foundation for Statistical Computing (2007) R statistical environment. Vienna (Austria). Available: http://www.r-project.org/. Accessed 18 July 2008.

31. Glantz S, Balbach E (2000) Tobacco war: Inside the California battles. Berkeley: University of California Press. 336 p.

32. Baltagi BH, Griffin JM (2001) The econometrics of rational addiction: the case of cigarettes. Journal of Economic and Business Statistics 19: 449-454.

33. Gallet CA, List JA (2003) Cigarette demand: a meta-analysis of elasticities. Health Econ 12: 821-835.

34. Centers for Disease Control and Prevention (2007) Smoking \& Tobacco Use: Consumption Data. Available: http://www.cdc.gov/tobacco/ data_statistics/tables/economics/consump1.htm. Accessed 17 September 2007.

35. Centers for Disease Control and Prevention (2007) Percentage of adults who were current, former, or never smokers. http://www.cdc.gov/tobacco/ data_statistics/tables/adult/table_2.htm. Accessed September 17, 2007.

36. Sloan FA, Ostermann J, Picone G, Conover C, Taylor D Jr. (2004) The price of smoking. Cambridge (Massachusetts): MIT Press.

37. Centers for Disease Control and Prevention (2008) Prevalence of Adult Smoking by State (BRFSS data). State Tobacco Activities Tracking and Evaluation (STATE) system. http://apps.nccd.cdc.gov/statesystem/. Accessed 15 April 2008.

38. Levy DT, Nikolayev L, Mumford E (2005) Recent trends in smoking and the role of public policies: results from the SimSmoke tobacco control policy simulation model. Addiction 100: 1526-1536.

39. Givel M, Glantz S (2001) Tobacco lobby political influence on US state legislatures in the 1990s. Tob Control 10: 124-134.

40. Givel M, Glantz S (2002) State tobacco settlement funds not being spent on vigorous tobacco control efforts. Oncology 16: 152, 155-157.

41. Ling PM, Glantz SA (2005) Tobacco industry consumer research on socially acceptable cigarettes. Tob Control 14: e3. 


\section{Editors' Summary}

Background According to the World Health Organization (WHO) tobacco causes 1 in 10 adult deaths worldwide and is the leading preventable cause of death in the world. In 2005, tobacco caused 5.4 million deaths, which amounts to one death every 6 seconds. It is estimated that by 2030, annual deaths from tobacco use will be 8 million worldwide. Eighty percent of these deaths will occur in the developing world.

Exposure to secondhand tobacco smoke is also a major health concern as it can cause cancer, heart disease, and respiratory illness. An estimated 200,000 workers die annually from exposure to smoke at work, according to the International Labour Organization.

In 2008, the WHO released a report on the global tobacco epidemic, which provided a comprehensive analysis of tobacco use and control efforts. It revealed that not a single country fully implements all key tobacco control measures. The report also stated that governments around the world collect 500 times more money in tobacco taxes each year than they spend on anti-tobacco efforts.

The California Tobacco Control Program (CTCP) is a state-funded public policy intervention established in 1989. Its goal is to decrease tobaccorelated diseases and deaths in California by reducing tobacco use across the state. The program is focused on adults and social norm change rather than on adolescent tobacco use prevention, on the premise that the "next generation cannot be saved without changing the generations who have already reached adulthood."

Why Was This Study Done? The success of large public health programs, especially those that counter the tactics of powerful industries such as the tobacco industry, require funding. The justification of public spending on these initiatives should be evidence driven. While the success of the CTCP in reducing smoking was known, it was not yet clear whether the program had reduced health care costs. The researchers investigated the effect of the CTCP on personal health care expenditures in the state. Their findings can provide useful information for the development of other tobacco control initiatives.

What Did the Researchers Do and Find? Using the statistical approach of cointegrating regressions, the researchers modeled the relationships between per capita tobacco control expenditures, per capita cigarette consumption, and health care expenditures. They analyzed data from 1980 and 2004 on smoking, health care expenditures, and exposure to a tobacco control educational program in California and compared them to a group of 38 control states. Control states were those without comprehensive tobacco control programs prior to 2000 or cigarette tax increases of $\$ 0.50$ or more per pack over the study period. This comparison allowed the researchers to assess the effect of the CTCP on total personal health care spending.
The researchers found that US\$86 billion $(95 \% \mathrm{Cl} \$ 28$ billion to $\$ 151$ billion) were saved in personal health care expenditure between 1989 , the start of the program, and 2004. This generally grew over time, reaching $7.3 \%$ of the total in 2003-2004. The personal health care expenditure savings represented about a 50 -fold return on the $\$ 1.8$ billion spent on the program during the same period (all 2004 US dollars).

The researchers report that 3.6 billion ( $95 \% \mathrm{Cl} 1.5$ billion to 5.9 billion) fewer packs of cigarettes were sold between 1989-1990 and 2003-2004. This represents a loss of $\$ 9.2$ billion $(95 \% \mathrm{Cl} \$ 3.8$ billion to $\$ 14.7$ billion) to the tobacco industry in pre-tax cigarette sales.

These cost savings occurred despite the substantial diversion of funding and decreased purchasing power experienced by the CTCP, particularly in the mid-1990s. (The program was funded with a constant tax of $\$ 0.05$ per pack, despite inflation). The researchers estimated that if the funding, and thus purchasing power, had been maintained, total savings in personal health expenditures would have increased to $\$ 156$ billion with an additional $\$ 70$ billion in health cost savings. Cigarette consumption would have dropped to an estimated 6.6 billion packs.

What Do These Findings Mean? The CTCP has been successful in reducing smoking in California in comparison to other states, and has reduced personal health care expenditures. These cost reductions were substantial, rapid, and grew over time. The researchers contend that the CTCP's focus on social norm change among adults, not primarily on youth prevention, is responsible for such rapid and large reductions in disease and the associated health care costs. They state that a program focused on primary prevention of smoking among adolescents would take decades to have any impact on tobacco-induced diseases, which rarely manifest among adolescents or even young adults. These researcher's findings support the establishment of strong tobacco control programs in other settings: they not only reduce smoking, prevent disease, and save lives, but also represent an important way to curb rapidly increasing health care expenditures in the short term.

Additional Information. Please access these Web sites via the online version of this summary at http://dx.doi.org/10.1371/journal.pmed. 0050178.

- The California Tobacco Control Program provides information about its social change approach

- The WHO MPOWER strategy, detailed in the 2008 Report on the Global Tobacco Epidemic, outlines the six most effective policies to help curb the epidemic

- Resources to help people quit smoking can be obtained through the US Centers for Disease Control and the UK National Health Service 